\title{
CURAS ILEGAIS E REPRESSÃO NO OITOCENTOS ESPIRITO SANTENSE: OS CASOS DE TREM E OLEGARIO
}

(1D) Sebastião Pimentel Franco ${ }^{I ; 2}$

(D) André Luis Lima Nogueira ${ }^{34}$

\section{RESUMO}

O presente artigo objetiva tratar das práticas terapêuticas ilegais de dois curadores que atuaram no Espírito Santo do século XIX: Antônio Damazio Camilo, conhecido como "o Trem",e Olegário dos Santos.Os processos-crime que atestam a repressão de suas práticas serão analisados a partir de alguns vetores fundamentais: como se davam os mecanismos de coerção e de afirmação da medicina douta no Império e no começo da República; que tipo de práticas terapêuticas (analisadas em perspectiva morfológica) e matrizes culturais podemos identificar nas ações dos curadores e que tipo de relações de sociabilidade estariam por trás de suas ações de cura.

\section{PALAVRAS-CHAVE}

Práticas de cura - medicina imperial -Espírito Santo - século XIX.

I Universidade Federal do Espírito Santo - Vitória - Espírito Santo - Brasil.

2 Doutor em História pela Universidade de São Paulo. Professor Titular e do Programa de Pós-Graduação em História da Universidade Federal do Espírito Santo (UFES). Autor, entre outros livros, de O Terribilíssimo Mal do Oriente:o cólera da província do Espírito Santo (1855-1856) (EDUFES, 2015), e da organização, com a colaboração de outros pesquisadores, da coletânea Uma História Brasileira das Doenças, vols. 4, 5, 6 e 7.sp.franco61@gmail.com.

3 Fundação Oswaldo Cruz (Fiocruz)/ FAPERJ. Rio de Janeiro - Rio de Janeiro - Brasil.

4 Doutor em História das Ciências e da Saúde pela Fundação Oswaldo Cruz (COC/FIOCRUZ). Atualmente está no Programa de Pós-doutorado Nota 10 da Fundação Carlos Chagas Filho de Amparo à Pesquisa do Estado do Rio de Janeiro, na mesma instituição (FAPERJ/FIOCRUZ). autor de Entre Cirurgiões, Tambores e Ervas: calunduzeiros e curadores ilegais em ação nas Minas Gerais (século XVIII) (Garamond, 2016), além de artigos e capítulos em livros.guazoo8@gmail.com 


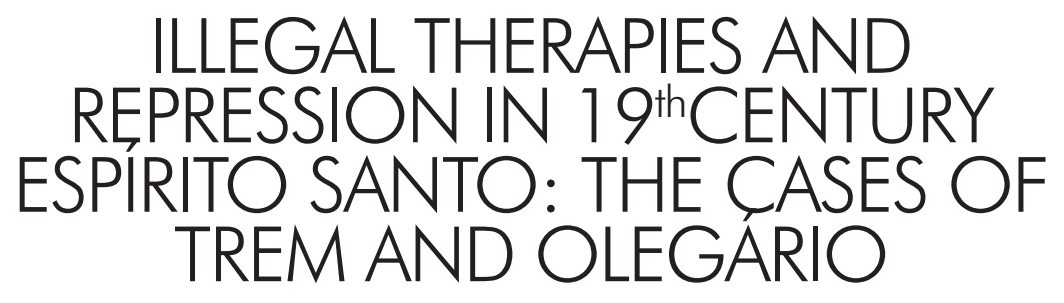

(D) Sebastião Pimentel Franco

(D) André Luis Lima Nogueira

The present article aims at addressing the illegal therapeutic practices of two healers who worked in the state of Espírito Santo in the $19^{\text {th }}$ century: Trem and Olegário dos Santos. The criminal proceedings that have suppressed their practices will be analyzed in the light of some key vectors: how learned medicine's mechanisms of coercion and enforcement took place during the Empire and at the beginning of the Republic; we will also consider what sort of therapeutic practices (analyzed under a morphological perspective) and what cultural matrices can be identified in the healers' actions, as well as what sort of sociability relations lie behind their curing deeds.

\section{KEYWORDS}

Curing practices - imperial medicine - Espírito Santo $19^{\text {th }}$ century. 
omo é sabido, as práticas e saberes médicos ganharam novos contornos com a chegada da família Real portuguesa ao Brasil em 1808. Uma importante providência tomada pelo príncipe regente, D. João, em terras brasileiras foi a criação do curso de Medicina no Rio de Janeiro e na Bahia.A criação dessas "escolas” teve como consequência a ampliação do número de médicos que passaram a atuar no Brasil, em especial nas áreas mais densamente povoadas.

A criação desses cursos, no entanto, não significou que,a partir de então, o saber médico se difundiu no seio da população e que as práticas de curar não emanadas dos doutos tenham simplesmente desaparecido.

O número cada vez maior de médicos, aliado à presença de grandes epidemias que assolaram o Brasil a partir da segunda metade do século XIX, acarretou desse momento em diante uma disputa pelo saber médico, na medida em que todo conhecimento que não fosse emanado dos profissionais formados pelas academias de medicina era rejeitado e desconsiderado5. Obviamente, essa negação de todo e qualquer saber médico que não fosse oriundo dos doutores em Medicina não foi uma luta fácil, sendo a duras penas que os médicos conseguiram afirmar sua autoridade científica. Para conseguirem tal intento, estes se impuseram sob dois aspectos: habilidade técnica e poder social, como afirma Pierre Bourdieu6 . Segundo Keila Carvalho, essa autoridade se deu no Brasil em razão de socialmente ser atribuído a esses profissionais a possibilidade de "[...] falar e agir legi-

5 KODAMA, Kaori et al. Mortalidade escrava durante a epidemia de cólera no Rio de Janeiro (18551856): uma análise preliminar. História, Ciências, Saúde-Manguinhos, Rio de Janeiro, v. 19, pp. 5979, 2012. Suplemento 1; FRANCO, Sebastião Pimentel. O terribilíssimo mal do Oriente: o cólera na província do Espírito Santo (1855-1856). Vitória: Edufes, 2015; BELTRÃO, Jane Felipe. A arte de curar dos profissionais de saúde popular em tempo de cólera: Grão-Pará do século XIX. História, Ciências, Saúde-Manguinhos, Rio de Janeiro, n. 6, pp. 833-866, set. 2000.

6 BOURDIEU, Pierre. The specificity of the scientific field and the social conditions of the progress of reason. Social Science Information, v. 14, n. 6, pp. 19-47, 1975. 
timamente, de forma autorizada e, muitas vezes, autoritária, sobre questões científicas"?.

A nos reportarmos a essa situação, estamos concordando com o pensamento da nova historiografia brasileira que, na contramão de Roberto Machado ${ }^{8}$, seguidor do pensamento foucaltiano, asseveravaque teriam os médicos mudado de forma radical as condutas e valores da sociedade brasileira no que tange à condenação do saber médico popular. Dessa forma, compactuamos com os historiadores que buscam interpretações diferentes da corrente foucaultiana, como Gilberto Hochman e Diego Armus, concebendo que "[...] as dimensões do cuidar, controlar, curar [...] não devem ser entendidas como compostas unicamente de relações unidirecionais, imutáveis e verticais de poder estabelecidas como sucessivos pares de subordinações hierárquicas".

Assim, como pensava a maioria da população de outras localidades do Brasil, a do Espírito Santo, ao enfrentar doenças, sobretudo as epidemias que assolaram a província a partir no Oitocentos, recorreu sim à medicina douta, sem, no entanto, deixar de se utilizar de conhecimentos médicos que aprendeucom seus antepassados ou mesmo de recorrera curadores como AntonioDamazio Camillo (vulgo Trem) e Olegário Lima dos Santos -atuantes nacomarca de Vitória -, na expectativa de solucionar os males que a afligia. A busca por práticas de cura diferentes das apregoadas pelos médicos evidencia que

7 CARVALHO, Keila. A saúde pelo progresso: a regulamentação do trabalho médico no governo Vargas (Minas Gerais, 1930-1940). Rio de Janeiro: Multifoco, 2015.p. 15.

8 MACHADO, Roberto et al.Danação da norma. Medicina social e construção da Psiquiatria no Brasil. Rio de Janeiro: Graal, 1978.

9 HOCHMAN, Gilberto; ARMUS, Diego (org.). Cuidar, controlar, curar em perspectiva histórica: uma introdução: ensaios históricos sobre saúde e doença na América Latina e Caribe. Rio de Janeiro: Editora Fiocruz, 2004. Para uma percepção análoga e uma crítica bastante convincente ao conceito foucaultiano de "medicalização da sociedade", ver FERREIRA, Luís O. Medicina impopular: ciência médica e medicina popular nas páginas dos periódicos científicos (1830-1840). In: CHALHOUB, Sidney et al. (org.). Artes e oficios de curar no Brasil: capítulos de história social. Campinas: Editora Unicamp, 2003. p. 101-122. 
a população, tal como apontam Hochman e Armus, se insubordinava e contestava os saberes oficiais ${ }^{10}$.

Neste sentido, um questionamentoserve de ponto de partida para nossas investigações: por que havia espaços para contestações da população ao "saber médico-científico"? Tentando responder a essa pergunta, argumentamos que ao surgirem as grandes epidemias do Oitocentos "[...] os médicos que atuavam no Brasil defendiam diferentes posicionamentos, os quais tinham ligação direta com a sua formação. Alopatas e homeopatas sustentavam posições antagônicas quanto às indicações de tratamento da enfermidade"11.

Para além dos embates com os homeopatas, os alopatas, ao se aproximarem do poder e do discursogovernamental, acionaram uma guerra contra aqueles que não possuíam formação médica oficial. Perseguições tornaram-se prática corrente no intuito de afastar a população de recorrer aos curadores que chamavam depreciativamente de charlatães ${ }^{12}$, que nos termos dos representantes da medicina douta, seriam todos aqueles indivíduos que curavam "ilegitimamente", em geral não possuindo diplomas ou licenças. Nesta perspectiva, nosso olhar se alinha ao de outros autores na percepção de que havia "várias/diferentes medicinas" - tanto legais como ilegais - à disposição dos enfermos em busca de cura no período imperial ${ }^{13}$.

Propomos evidenciar, neste texto, a coexistência dos saberes médicos populares e da medicina oficial, como a observada na ação de se recorrer a curadores não diplomados para alíviodos males que afligiam a população cotidianamente. Para entendermos melhor a

10 HOCHMAN, Gilberto; ARMUS, Diego. Op. cit.p. 48.

11 Ibidem, p. 15.

12 Sobrea forma com que os médicos manipulavam e definiam a categoria "charlatão", indicamos a leitura do médico Imbert (1857), doutor em Medicina pela Universidade de Montpellier, com título reconhecido pela Faculdade de Medicina do Rio de Janeiro.

13 Conferir, XAVIER, Regina. Dos males e suas curas. Práticas médicas na Campinas oitocentista. In: CHALHOUB, Sidney et al. Op. cit., p. 331-354. EDLER, Flávio C. Medicina no Brasil imperial: clima, parasitas e patologia tropical. Rio de Janeiro: FIOCRUZ, 2011; SAMPAIO, Gabriela. Nas Trincheiras da Cura. As diferentes medicinas no Rio de Janeiro Imperial. São Paulo: Editora daUnicamp, 2001. 
prática disseminada da utilização de tais terapeutas por parte da população capixaba no Oitocentos, recorremos a doisautos criminais, que documentam as situações nas quais os curadores já citados foram levados "às barras da Justiça” por estarem atuando ilegalmente na prática médica, uma vez que não possuíam o "saber científico”. Tal situação certamente ocorreu, visto que já estava sedimentado, nessa época, esse "saber científico" como único possível quanto ao exercício da cura. Dessa forma, discutiremos ainda o embate que tomava conta do país à época sobre quem poderia exercer a prática de cura. Por fim, pretendemos verificar como atuavam esses curandeiros e como conseguiam se movimentar atraindo significativo número de pessoas sob sua órbita.

Incialmente, iremos promover uma discussão teórica sobre o uso de processos crimes como fonte evidenciar práticas cotidianas, em seguida buscaremos traçar uma breve radiografia da Comarca de Vitória - espaço de atuação dos personagens aqui analisados - no Oitocentos.

\section{Processos-crime como fonte histórica}

Desde as décadas de 1980 e 1990, é possível observar historiadores brasileiros - como Leila MezanAlgranti, Rachel Soihet, Sidney Chalhoub, Celeste Zenha, Hebe Maria Mattos ${ }^{14}$, dentre outros - se debruçando sobre processos-crime para desvendar o viver- ou para buscar compreender como se comportavam - segmentos sociais no seu cotidiano, uma vez que por meio desta documentação é possível enxergar detalhes da vida íntima da população ao perscrutar seu dia

14 ALGRANTI,Leila Mezan. O feitor ausente: estudos sobre a escravidão urbana no Rio de Janeiro (1808-1822). Rio de janeiro: Vozes, 1988.CHALHOUB, Sidney. Trabalho, lar e botequim: o cotidiano dos trabalhadores do Rio de Janeiro da Belle Époque. 2. ed. Campinas/São Paulo: Editora da Unicamp, 1986.SOIHET, Rachel. Vivências e formas de violência: mulheres pobres e ordem urbana (1890-1920). Rio de Janeiro: Forense Universitária, 1989.MATTOS, Hebe Maria de Castro. Das cores do silêncio: os significados da liberdade no sudeste escravista-Brasil, século XIX. 2. ed. Rio de Janeiro: Nova Fronteira, 1998.ZENHA, Celeste. As práticas da justiça no cotidiano da pobreza. Revista Brasileira de História,São Paulo, v. 5, n. 10, pp. 123-146, mar/ago. 1995. 
a dia. Assim, através das informações presentes nosprocessos-crime, são desvelados suas vidas íntimas, laços afetivos, laços familiares desse segmento social, "registrando o corriqueiro de suas existências, seus valores morais, éticos, suas crenças" ${ }^{15}$, buscando enxergar comportamentos sociais e formas de se construir a ordem.

Para Maria Cristina Martinez Sato, os processos criminais, embora sejam versões dos fatos, nos possibilitam enxergar o vivido, pois não importa que a versão apresentada tenha por objetivo incriminar ou livrar o réu da acusação, na medida em que

[...] mesmo não sendo totalmente fidedignas [as versões produzidas], são dotadas de sentido e capazes de explicar os atos envolvidos. Assim, essas formulações ganham relevo à medida que são portadoras de valores culturais. Por meio da investigação das circunstâncias e motivações dos crimes e da análise das diferentes versões podemos nos aproximar dos laços culturais existentes entre indivíduos ${ }^{16}$.

Embora não possamos negar que os processos-crime nos permitem perceber, no dizer de Joana Maria Pedro, a trama das relações sociais, "[...] a concretude do cotidiano [percebendo] a trama das relações se fazendo [...]", não podemos nos esquecer, como diz a referida autora, que nós historiadores devemos entender os percalços que esse tipo de fonte pode nos apresentar, já que as falas presentes nos autos - quer das testemunhas, réus ou vítimas -, eram filtradas pelo escrivão. "Da parte dos acusados àquilo que acreditam que os homens do aparato jurídico querem ouvir, procurando fugir assim à incriminação. Como acreditar em seus depoimentos? Como ver neles a concretude do cotidiano"17. Da mesma forma pensa Celeste Zenha,

15 SOUZA, Alinaldo Faria de. Entre a reclusão e o enfrentamento: a realidade da condição feminina no Espírito Santo a partir de autos criminais (1845-1870) - desmistificando estereótipos. 2007. 143

f. Dissertação (Mestrado em História).Centro de Ciências Humanas e Naturais,Universidade Federal do Espírito Santo, Vitória, Espírito Santo, 2007. p. 19.

16 SATO, Maria Cristina Martinez. Pobreza e conflito (1860-1935). São Paulo: Annablume, 2001. p. 28. 17 PEDRO, Joana Maria. Processo judiciais como fonte histórica: a concretude e o uso. In: SIMPÓSIO

NACIONAL DE HISTÓRIA, 26., 2011, São Paulo. Anais do XXVI Simpósio Nacional da Associação 
ao dizer que essa fonte apresenta versões diferentes dificultando se chegar aos fatos como teriam acontecido ${ }^{18}$.

O trato desse tipo de fonte para nos evidenciar o cotidiano da vida da população do Espírito Santo no Oitocentos é algo recente na historiografia capixaba, cabe registrar que os trabalhos existentes referem-se a vida de escravos como o de Campos e Merlo, o de Mergár e Souza, referentes à condição feminina e ainda o de Câmara, sobre a violência ${ }^{19}$.

\section{O viver cotidiano, cenário de atuação dos acusados}

Os processos-crimesobre o quais ora estamos nos debruçando aconteceram em localidades diferentes. Um ocorreu na capital Vitória e outro, em Viana. Entretanto, ambas as localidades faziam parte da Comarca de Vitória. A distância (cerca de 30 quilômetros) entre essas duas localidades era bastante razoável para época, uma vez que não existiam estradas de comunicação entre elas.

A cidade de Vitória, por ser a capital primeiramente da província e depois do Estado do Espírito Santo, possuía o maior contingente populacional, que variou no decorrer do Oitocentos. Examinando relatórios de Presidente de Província e de Estado pode-se evidenciar tal questão. Em 1856, por exemplo, Vitória possuía 14.643 habitantes,

Nacional de História São Paulo: ANPUH, 2011. p. 31.

18 ZENHA. Op. cit.,p. 135.

19 MERLO, Patrícia Maria da Silva. O nó e o ninho: estudo sobre a família escrava em Vitória, Espírito Santo, 1900-1871. 2008. Tese (Doutorado em História). Instituto de História, Universidade Federal do Rio de Janeiro, Rio de Janeiro, 2008.CAMPOS, Adriana Pereira. Nas barras dos tribunais: Direito e escravidão no Espírito Santo do século XIX. Tese (Doutorado em História). Instituto de História, Universidade Federal do Rio de Janeiro, Rio de Janeiro, 2003.CÂMARA, Raphael Americano. Cotidiano, violência e criminalidade na comarca de Vitória/ES, a partir dos autos criminais (1841-1871). 2013. 170 f. Dissertação (Mestrado em História). Centro de Ciências Humanas e Naturais, Universidade Federal do Espírito Santo, Vitória, Espírito Santo, 2013; MERGÁR, Arion. A representação do gênero feminino nos autos criminais na Província do Espírito Santo (1853-1870). 2006. 160 f. Dissertação (Mestrado em História). Centro de Ciências Humanas e Naturais, Universidade Federal do Espírito Santo, Vitória, Espírito Santo, 2006; SOUZA, Alinaldo Faria de. Op. cit. 
enquanto Viana apresentava um total de $3.502^{20}$. Quinze anos depois, em 1871, a população de Vitória era de 17.700 almas e a de Viana, 4.996 moradores.

Em Vitória, a maioria da população vivia nas áreas urbanizadas e um número menor habitava nas áreas rurais da capital. Em Viana, o processo era o contrário: a maioria da população vivia em pequenas propriedades, dedicando-se ao cuidado do seu pequeno roçado, de onde tiravam o sustento daquilo que plantavam e colhiam, além da criação de animais como aves, porcos e gado. Alguns realizavam ainda a atividade da pesca como forma de complementar o sustento diário.

Tanto em Vitória como em Viana, a maioria dos moradores eram pessoas simples, que viviam pobremente, garantindo a sobrevivência por meio da faina diária. Na capital, existia um pequeno percentual de endinheirados, que viviam de seu comércio, do trabalho em funções administrativas do Estado ou, ainda, do trabalho como profissional liberal (médicos, advogados, engenheiros) e de rendas advindas de aluguéis ou de dinheiro emprestado a juros.

Dos personagens presentes nos processos-crimeaqui analisados, 20 eram lavradores, 2eram jornaleiros e um apresentava-se como curandeiro.

A maioria da população de ambas as localidades era analfabeta. Não podemos esquecer que no Oitocentos no Espírito Santo, o número de escolas era restrito, sendo esse contingente para as mulheres ainda bem menor. ${ }^{21}$ Em estudos realizados a partir de autos criminais

20 RELATÓRIO com que o Barão do Itapemirim primeiro vice-presidente da Província do Espírito Santo apresentou na abertura da Assembleia Legislativa Provincial no dia 23 de maio de 1857. Victoria: TypographiaCapitaniense de P. A. d'Azeredo, 1857.

21 Embora no decorrer do século XIX o discurso em favor da instrução estavase solidificando, o que se verificana prática é quea maioria da população eraanalfabeta. Não podemos esquecer que durante boaparte do século XIX, mulheres e escravos estiveram alijados do processo de escolarização. No caso das mulheres, somente a partir de 1845 é que surge a primeira escola para meninas, embora essa escola tivesse sido criada por lei em 1835. Sobre o processo de escolarização no Espírito Santo no Oitocentos, indicamos as seguintes leituras: FRANCO, Sebastião Pimentel. A instrução feminina na visão dos presidentes da província do Espírito Santo (1845-1888). In: ; SÁ, Nicanor Palhares (org.). Gênero, etnia e movimentos sociais na história da educação. 
do Oitocentos na Província do Espírito Santo, ArionMergár, Souza e Raphael Americano Câmara já apontaram que, dos personagens presentes nos autos criminais com os quais trabalharam, a grande maioria era analfabeta. Ao nos debruçarmos sobre os autos que estamos analisando, verificamos que, dos 23 personagens presentes (réus e testemunhas), 20 eram analfabetos ${ }^{22}$.

A maioria dos habitantes dessas localidades deveria ser solteira ${ }^{23}$, embora dos 23 personagens presentes nos autos criminais com os quais estamos trabalhando, tenhamos encontrado um número maior de casados: 12 contra 11 solteiros. Em trabalhos já citados, Mergár, Souza e Câmara apresentam dados que apontam que a maioria da população capixaba do Oitocentoserasolteira.

\section{Os curandeiros Antônio Damasio e Olegário Lima dos Santos nas malhas da Justiça}

A partir de agora nos interessará discutir as curas efetuadas por Antônio Damasio, também conhecido como Trem, e Olegário Lima dos Santos, descrevendo-as do ponto de vista morfológico e sublinhando certas similitudes existentes entre elas. Buscaremos, igualmente, refletir sobre os significados e crenças acionados por esses curadores. Nestas podemos perceber a presença da religião católica, nem sempre vivida como rezava a ortodoxia e eivada de originalida-

Vitória: Edufes, 2011.p. 85-122. FRANCO, Sebastião Pimentel. Do privado ao público: o papel da escolarização na ampliação de espaços para a mulher na Primeira República. 2001. 295 f. Tese (Doutorado em História Social).Faculdade de Filosofia, Letras e Ciências Humanas,Universidade de São Paulo, São Paulo, 2001.

22 MERGAR. Op. cit.,p. 88 e seguintes. SOUZA. Op. cit.,p. 45; CÂMARA. Op. cit.,p. 52 e seguintes. 23 Eni Mesquita Samara e Maria Beatriz Nizza da Silva reportando-se a essa questão afirmam que, de forma geral, a maioria da população brasileira era celibatária, embora vivesse em concubinato na grande maioria em relações consensuais estáveis. Cf. SAMARA, Eni Mesquita. A família brasileira. 2. ed. São Paulo: Brasiliense, 1986.SILVA, Maria Beatriz Nizza da. Sistema de casamento no Brasil colonial. São Paulo: Edusp, 1984. 
des e de um intenso processo de crioulização, com elementos culturais de matizes africanos ${ }^{24}$.

Da fala das testemunhas emerge, igualmente, uma intensa rede de sociabilidade entre os dois curadores e as comunidades na qual atuavam. Sentimentos ambíguos como ódio, admiração e descrença se fazem notar nas falas daqueles que conheciam os -ou mesmo tinham recorrido aos - préstimos de Antônio e Olegário. Para estes, saber curar e entrar em contato com o "outro mundo" rendiam-lhes visibilidade e bens materiais, além de parecerem circular com desenvoltura pelos diferentes estratos sociais, atendendo, indistintamente, tanto indivíduos abastados como a arraia-miúda que acreditava em suas terapêuticas.

Entre os dois processos passaram-se vinte anos. Aliás, tempos de intensas mudanças no Brasil. Entre 1879 e 1899acontecimentos como o fim da escravidão e a proclamação da República trouxeram alterações de relevo. Uma delas, e que mais diretamente toca a temática desse artigo, foi a aprovação de um novo Código Penal em 1890. Este seria marcado pelo recrudescimento da perseguição contra uma miríade de práticas terapêuticas e, não raro, às manifestações religiosas a elas ligadas, que de acordo com o juízo das autoridades republicanas seriam passíveis de coerção por não se enquadrarem no que seria admitido como uma verdadeira e legítima religião $0^{25}$. Em consonância com esse tipo de percepção, Gabriela Sampaio, valendo-se fundamentalmente de periódicos como fonte, sublinha a existência de uma série de matérias nos diferentes jornais que abonavam tais práticas

24 Em vista dos limites físicos de um artigo, torna-se inviável a explicitação mais pormenorizada do escopo teórico-metodológico que embalou a leitura e análise das fontes. Entretanto, vale sublinhar que lançamos mão do conceito de "crioulização" com base, entre outros autores, nas leituras de FERREIRA, Roquinaldo. "Ilhas crioulas": o significado plural da mestiçagem cultural na África atlântica. Revista de História, São Paulo, n. 155, 2º, pp. 17-41, 2006.PARÉS, Luís N. O Processo de crioulização no Recôncavo baiano. Afro-Ásia, Salvador, n. 33, pp. 87-132, 2005.

25 ORO, Ari Pedro. Considerações sobre a liberdade religiosa no Brasil. Ciências $\&$ Letras, n.37,pp.433-447, 2006. p. 450 e seguintes. 
coercitivas em nome de extirpar, como defendiam os editores e colaboradores dos veículos, tais "superstições bárbaras e atrasadas"26.

Assim, o Código Penal de 1890possuía três artigos específicos para dar conta desse tipo de delito:

Art. 156 - Exercer a medicina em qualquer dos seus ramos e a arte dentária ou farmácia: praticar a homeopatia, a dosimetria, o hipnotismo ou o magnetismo animal, sem estar habilitado segundo as leis e regulamentos.

Art. 157 - Praticar o espiritismo, a magia e seus sortilégios, usar talismãs e cartomancias para despertar sentimentos de ódio e amor, inculcar cura de moléstias curáveis ou incuráveis, enfim para facilitar e subjugar a credulidade pública.

Art. 158 - Ministrar, ou simplesmente prescrever, como meio curativo para uso interno ou externo e sob qualquer forma preparada, substância de qualquer dos reinos da natureza, fazendo, ou exercendo assim, o ofício denominado de curandeiro (BRASIL, 1890) ${ }^{27}$.

Como é possível perceber a partir do texto dos artigos, a repressão imposta ao "espiritismo" - como qualifica num termo guarda-chuva o Código Penal - acabava centrando-se na ideia de que tais práticas envolviam, sobremaneira, o exercício ilegal da medicina. No que versa sobre mais precisamente às práticas religiosas e de cura de matizes africanos, conforme argumenta Mário Sá Jr, o texto da lei garantia a criminalização do que o autor chama "tripé básico da macumba": o curandeirismo, a magia e a feitiçaria ${ }^{28}$.

26 SAMPAIO, Gabriela. "Curandeiros e Charlatães": reflexões sobre medicina, crença e cura na primeira década republicana. mneme - revista de humanidades, Caicó, v. 15, n. 34, pp. 37-53, jan./ jun. 2014. p. 38.

27 COLEÇÃO de leis do Brasil. Decreto $n^{\circ}$ 847, de 11 de outubro de 1890. Disponível em: <http:// www2.camara.leg.br/legin/fed/decret/1824-1899/decreto-847-11-outubro-1890-503086-publicacaooriginal-1-pe.html>. Acesso em:18 mar. 2018. Optamos pela atualização da grafia da documentação pesquisada.

28 SÁ JR. Mário. Fé cega justiça amolada. O controle do Judiciário sobre as práticas religiosas afro-brasileiras no nascimento da República (1891-1946). Revista Brasileira de História das Religiões, 
Embora esse vetor não se faça objeto deste artigo, devemos ainda lembrar que uma parte fulcral da aprovação de um Código Penal com as características acima mencionadas, bem como outras ações no sentido de afirmar a República como o regime do "novo", do "progresso", era parte de um projeto de nação mais amplo.Aliás, este projeto já estava em curso desde as últimas décadas do século XIX,momento em que, dentre outros aspectos, seria fortemente marcado pela tradução e reinterpretação das teorias racialistas - em voga nos ambientes europeus no período -, por vários agentes e instituições científicas no Brasil no afã de superar a "barbárie" da escravidão, da miscigenação e da presença, sempre pulsante, de matizes culturais africanos ${ }^{29}$.

\section{"Respondeu ser curandeiro"}

Desse modo o escrivão Fonseca anotara a resposta de Antônio Damasio Camillo, vulgo Trem, ao questionamento do delegado acerca de sua ocupação. À época do processo, contava com seus trinta e oito anos de idade e morava na capital da Província, Vitória, sendo natural da região de Valença, no Rio de Janeiro. Infelizmente, não há no processo nenhuma menção à condição jurídica de Antônio Damasio. O fato é que era oriundo de uma área de grandes propriedades de produção de café para a exportação, com altas taxas de incidência de populações africanas. Mais provável, até, que fosse um homem livre ou liberto, em função de sua mobilidade, além do fato de não haver a menção direta em seu processo da condição cativa, o que era mais recorrente nesse tipo de documentação.

Conforme argumenta Hebe Mattos, o fator "maior possibilidade de circulação" era um diferencial bastante visível e valorizado na diferenciação entre aqueles que viveram o mundo do cativeiro e, posteriormente, buscavam afirmar sua nova condição de homens e

Maringá,v. III, n.9, pp. 1-9, jan.2011. Disponível em: $<$ http://www.dhi.uem.br/gtreligiao/pub. html . Acesso em: 20 mar. 2018.

29 SCHWARCZ, Lilia. Espetáculo das raças: cientistas, instituições e questão racial no Brasil (18701930). São Paulo: Cia das Letras, 1993. 
mulheres libertos ${ }^{30}$.Por outro lado, ao se debruçar sobre as alforrias e as dinâmicas da escravidão no Espírito Santo das últimas décadas da escravidão, Geraldo Soares nos mostra que muitos dos cativos da Província possuíam uma liberdade de circulação bastante significati$\mathrm{va}^{31}$. Infelizmente, para o caso do curandeiro aqui analisado, a lacuna na documentação não nos permite afirmar peremptoriamente sobre a sua condição jurídica.

A atitude de afirmar ser curandeiro (o que indicaria, naturalmente, um "meio de vida") era bastante rara entre os indivíduos que seriam alvos de perseguições, sendo bem mais comum, por razões elementares, negar tais ações ou, pelo menos, colocá-las como subsidiárias a outras formas de garantia de sustento. Contudo, o Trem, a certa altura de seu interrogatório, tentou estrategicamente diminuir o peso de suas práticas, comentando que "apenas" ensinara àparda Urbana uma receita para esta se ver livre dos feitiços que o curador alegou terem sido infringidos por uma crioula de nome Angélica. Arrematando que não fazia mais que "dar curativos" por meio de rezas dirigidas a Santo Antônio Pequenino ${ }^{32}$. Sendo perguntado pelo delegado se "sabia fazer feitiços", respondeu negativamente, acrescentando, uma vez mais, que só sabia curar e apenas por meio de orações.

Assim, para além (como será tratado adiante) do peso de orações e de parte da ritualística católica em muitas dessas ações de cura, não fica difícil imaginar que Damasio poderia ter mencionado "apenas" recurso às orações como meio de minimizar a ilegalidade de suas culpas em razão do peso das práticas votivas católicas para o conjunto das populações do Império. Aliás, conforme argumenta Reis ${ }^{33}$, tal população estaria bastante acostumada com devoções exteriorizadas

30 MATTOS. Op. cit.,p. 56 e seguintes.

31 SOARES, Geraldo. Esperanças e desventuras de escravos e libertos em Vitória e seus arredores ao final do século XIX. Revista Brasileira de História, v. 26, pp. 79-114, 2006.p. 82 e seguintes.

32 Processo 527. Caixa 688. 1879. Arquivo Público do Estado do Espírito Santo.As folhas dos processos não foram numeradas.

33 REIS, João J. A morte é uma festa. Ritos fúnebres e revolta popular no Brasil do século XIX.São Paulo: Cia das Letras, 1999. 
aos santos, como procissões, orações públicas, dentre outras manifestações votivas,tornando assim mais familiares suas terapêuticas, vistas pela Justiça como elemento de transgressão.

Uma de suas práticas mais narradas pelas testemunhas era a descoberta de feitiços e a extração de parafernálias como agulhas, vidros, unhas, ossos, cabelos que, segundo o curador, seriam a prova material da existência dos mesmos. Entretanto, a fala das testemunhas acabava revelando um conjunto mais amplo de ações que apenas as "rezas" que mencionarapara se esquivar, quando de seu interrogatório.

Assim, chamado a contar o que sabia Benedito, que era escravo de uma D. Josefina, falou de uma "ferida incurável que tinha na perna”. Ao examiná-la, Antônio Damasio asseverou que "estava carregada de feitiços", fazendo, em seguida, o seguinte ritual de cura:

[...] pedio que comprasse um copo, aguardente, e dois ovos, ato feito, pôs aguardente dentro do copo, e cozinhou os ovos, mandou os quebrar, e nada tinha dentro, para contas dele respondente [sic.] fez aparecer uma muda [moeda] de dez réis, que ele respondente conhecia que era artimanha. ${ }^{34}$

Já em seu depoimento, José das Neves Xavier repete, praticamente sem variações, as curas dos supostos feitiços que sofria através do uso de ovos cozidos em aguardente que propiciava a retirada dos mesmos, em seu caso, uma "unha de dedo polegar e um dente de alho". Acrescentando ainda que o Trem lhe dera "duas garrafas de cerveja com umas ervas dentro", informação refutada pelo acusado ao mencionar que as garrafas se encontravam "lacradas como vieram da fábrica”. Outra variação de suas práticas terapêuticas desmentida pelo réu foi narrada pela crioula Angélica Maria da Conceição, aquela acusada de ter feito feitiços contra Urbana. Sendo chamada a depor como testemunha, contou em juízo que a acusação de que teria enfei-

34 Processo 527. Caixa 688. 1879. Arquivo Público do Estado do Espírito Santo. 
tiçado Urbana se fez em razão de sua imagem aparecer "em uma bacia d'água vestida de vestido verde e tranças de cabelo”, numa alusão a um ritual de adivinhação engendrado pelo curador.

Como se pode notar, as principais ações terapêuticas agenciadas pelo Trem consistiam em descobrir feitiços por meio de rezas e de um ritual de quebrar ovos cozidos em aguardente para que os supostos feitiços fossem expelidos dos corpos enfermos. Entretanto, ao que parece, pela fala das testemunhas - todas desmentidas pelo curador -, suas práticas deveriam possuir mais variações. Podemos presumir que, ao desmenti-las, o Trem visava minimizar suas culpas, como já havia feito aliás no tribunal, dizendo que apenas curava através de orações a S. Antônio.

Parte dessas concepções de adoecimento e cura teria vida longa e, em certos momentos, não deixa de chamar atenção a proximidade das mesmas com os estudos atinentes à feitiçaria e às artes de curar do período colonial ${ }^{35}$. Desse modo, tais crenças na materialidade dos feitiços e na possibilidade de extraí-los pela destreza e poder de curandeiros encontravam-se bastante cristalizadas na segunda metade do século XIX e começo do século XX. Em seus estudos acerca do magismo e das práticas de cura no Rio Grande do Sul de inícios da República, Witter e Moreira, por exemplo, encontram um quadro bastante próximo daquele do Espírito Santo em época aproximada, no qual curadores, não raro de origem africana ou afrodescendentes, carregavam consigo cabelose insetos em vidros, como "prova" da cura bem-sucedida de feitiços ${ }^{36}$.

35 SOUZA, Laura de Mello e. O diabo e a Terra de Santa Cruz: feitiçaria e religiosidade popular no Brasil colonial. São Paulo: Cia das Letras, 1995.NOGUEIRA, André Luís Lima. Entre cirurgiões, tambores e ervas:calunduzeiros e curadores ilegais em ação nas Minas Gerais (século XVIII). Rio de Janeiro: Garamond Universitária, 2016.SÁ JR., Mário. Malungos do sertão. Cotidiano, práticas mágicas e feitiçaria no Mato-Grosso setecentista.Tese (Doutorado em História). Faculdade de Ciências e Letras de Assis, Universidade Estadual Paulista, 2008.

36 WITTER, Nikelen;MOREIRA, Paulo Roberto S. "Praticando a magia e seus sortilégios": feitiçaria e curandeirismo nos primórdios da República. In: DILLMANN, Mauro (org.). Religiões e religiosidades no Rio Grande do Sul: matriz afro-brasileira.vol. 4. São Paulo: ANPUH, 2016, pp. 21-48. p. 22 e seguintes. 
Os ovos e a aguardente, que aparecem de modo indisputável como os elementos mais centrais e lembrados das curas engendradas por Antônio Damasio, eram conhecidos de longa data nas práticas terapêuticas daqueles que curavam sem a chancela oficial.

Aliás, o uso de aguardente para fins terapêuticos também era bastante comum no curso do período colonial, sendo encontrado com frequência tanto nas práticas ilegais de cura como nos tratados de medicina.Este costume, a despeito do processo de institucionalização da medicina oficial e da afirmação de seus protocolos de ação, como já discutido acima, continuava presente nas práticas curativas do Império. Desse modo, nos "guias médicos" escritos, especialmente para um público mais amplo, a aguardente era usada em um sem número de receitas. No Dicionário de medicina popular..., escrito pelo médico polonês Napoleão Chernoviz, por exemplo, encontramos seu uso tanto interno - como numa receita contra o abatimento, sob o nome de elixir alimentício Ducro (aguardente, composto de carne e cascas de laranja) - como externo, para lavar abscessos, dentre muitas outras variadas aplicações no curso de seu tratado médico. ${ }^{37}$

Contudo, não podemos perder de vista que para as curas de feitiços realizadas pelo Trem, aaguardente possuía uma função flagrantemente ritual.Em Minas Gerais do século XVIII, numa denúncia reportada à justiça do bispado de Mariana contra os africanos Hyvo e sua mulher por práticas de certos rituais coletivos, é possível encontrar significativas analogias com as curas engendradas na província do Espírito Santo. Assim, os calunduzeiros das Gerais também se valiam de ovos em contato com os corpos enfermos, nesse caso, quebra-

37 CHERNOVIZ, Napoleão. Dicionário de medicina popular... Paris: A. Roger e F. Chernoviz, 1890.p .6 e 9. Acerca dos manuais médicos do dr.Chernoviz e sua extraordinária difusão, ver EDLER, Flávio e GUIMARÃES, Maria Regina C. Chernoviz e a medicina no Império. Insight Inteligência (Rio de Janeiro), Rio de Janeiro, n.23, pp. 128-146, 2003.FIGUEIREDO, Betânia Gonçalves. A arte de curar. Cirurgiões, médicos, boticários e curandeiros no século XIX em Minas Gerais. Rio de Janeiro: Vício de Leitura, 2002. 
dos na "coroa da cabeça”, a propósito de expelir os feitiços daqueles que os procuravam ${ }^{38}$.

Oriundo da região de Valença, como dito, com grande concentração populacional de africanos e afrodescendentes, ainda que não tivesse explicitada em seu processo sua condição jurídica e cor, o uso do ovo para a descoberta de feitiços pelo Trem nos parece filiado a matizes culturais africanos. Em vasto arco geográfico (ou, como preferem Chevalier e Gheerbrant, "por toda a África negra”), galinhas e galos são conhecidos mediadores entre "este" e o "outro" mundo, o que explica seu diversificado uso em ritos providencialistas, de adivinhação e de cura, que além do sacrifício desse animal, incluía, com frequência, igualmenteo recurso às suas penas e ovos ${ }^{39}$, como bem sabiam o curador de Vitória e os africanos das Gerais Hyvo e sua mulher.

\section{"Julgo ser bom curandeiro"}

Olegário Lima dos Santos sofreu um processo no ano de 1899, já sob o peso do novo Código Penal republicano, sendo preso e enredado nos artigos 157 e 158 (vide acima). Além disso, sua mulher Bárbara, Antônio Albino, Manuel Simões e Antônio Teodório foram juntamente implicados no artigo 21 (que se referia à cumplicidade em crimes). A justiça classificou as práticas de cura de Olegário e seus colaboradores da seguinte forma: "Fazendo crer que cura moléstias incuráveis, empregando ora a magia, ora prescrevendo internamente substancias de reino vegetal, exercendo assim o ofício de curandeiro"40.

Olegário era natural de Itapemirim, Espírito Santo, e respondeu ser jornaleiro de profissão, desvencilhando, assim, seu sustento das ações de cura. Era filho de uma escrava de nome Felicidade e, tal qual

38NOGUEIRA, André Luís Lima. Op. cit.,p. 243.

39CHEVAliER, Jean;GHEERbRANT, Alain. Dicionário de símbolos.Rio de Janeiro: José Olympio, 1998.p. 457-458.SWEET, James H. Recriar África.Cultura, parentesco e religião no mundo afro-português (1441-1770). Lisboa: Ed. 70, 2007. p. 188.

40 Processo 1.466. Caixa 745. 1899.Arquivo Público do Estado do Espírito Santo. 
muitos e muitos filhos de cativas, não pôde mencionar o nome de seu pai. Tinha no momento da prisão trinta e seis anos, o que indica ter vivido a experiência do cativeiro. Ao ser preso,nomeousete pessoas que havia curado, referindo que tais curas foram efetuadas por meio "apenas" do uso de plantas que curavam, como"mil homens", "pico de Nossa Senhora" e demais "folhas". Atitude análoga - excetuando o rompante de dizer "ser curandeiro" - àquela do Trem quando fora preso, visando minimizar suas ações. Entretanto, as testemunhas teriam mais o que dizer acerca das curas de Olegário.

O curandeiro de Viana, tal qual o Trem e tantos outros, curavam retirando animais e outras "imundícies" - conforme é comumente descrito nospapéis da repressão - de seus clientes sob a alegação de que seriam feitiços. Contudo, Olegário realizava rituais coletivos "pondo mesa" em diferentes lugares, mas, principalmente, na casa dos enfermos. Na denúncia proferida pelo promotor da Comarca que abre o processo, tais rituais seriam assim descritos:

$\mathrm{Na}$ casa onde existe uma pessoa doente ele se apresenta com os seus cúmplices, e aí coloca uma mesa, sobre a qual defronta vinho, velas e ervase depois de uma espécie de dança macabra a que se entrega com os seus companheiros, distribui o vinho com os assistentes, dizendo ser o sangue de Jesus Cristo; faz infusão das ervas e dá a erva ao doente, de cujo corpo, por uma [ileg.] de [ileg.] ou magia, faz crer que extraí um osso, [ileg.] de todo mal; outras vezes é um Grilo ou outro animal que ele arranca do corpo do doente, como há poucos dias se deu em casa de Fernando de tal. ${ }^{41}$

Ao ser chamado para depor, Gervásio Corrêa dos Passos teria dados novos a acrescentar a partir das perguntas direcionadas pelo delegado de polícia. Disse, tendo assistido numa ocasiãoàs cerimônias de cura engendradas por Olegário, que ao "por mesa" descobria feitiços com um "pão" (pau?) e que fez o doente expelir um osso apresentado por outras testemunhas como uma "presa de um porco"

41 Ibidem. 
- e depois Olegário o jogou no chão e, com a ajuda da mulher, "deitou pós” no osso para "matar” o feitiço. Em seguida, Gervásio narra o ritual como uma testemunha ocular:

Respondeu que usava de uma cantoria, o povo o acompanhava-o batendo palmas e ele dando um salto ficava pegado com os pés num pau, dizendo ele que estava sustentado pelos anjos que o iam levando; e os companheiros o chamaram para ele não ir para o céu; e que depois que ele voltava acabada a missa ele Olegario mandava que o Antonio Albino e Barbara [sua mulher] dessem o dito vinho ao povo, dizendo ser e ele que bebessem o sangue de Cristo ${ }^{42}$.

A testemunha acrescenta que vira Olegário "por mesa” a propósito de curar uma mulher de nome Vitória e que ele ainda "pôsuns pós na palma da mão e assoprava para os lados d'ela, dizendo para ir para o mar". Entretanto, a cura não fora bem sucedida e Vitória morreu na mesma noite, agravando ainda mais a situação do curador diante da Justiça.

Tomando em conjunto as falas das testemunhas, as cerimônias engendradas por Olegário, definidas como "por mesa” aos enfermos, eram centradas em danças, cânticoscadenciados por palmas, em partes compostos por trechos e/ou palavras que eram ininteligíveis para as testemunhas, conforme mencionou em seu depoimento Antônio Ferreira da Conceição, de que usaria "de linguagem desconhecida". Em seguida, o curador entrava em transe, como nos dá pistas a menção aos seus "trejeitos", o fato de "fingir ficar sem sentidos", "tremer e fazer acessos", conforme narrou várias das pessoas que presenciaram seus rituais. Uma vez em transe - "dizia o nome dos anjos que estava em seu interior" -,era quando administrava em seus enfermos beberagens a base de vinho e ervas, dizendo que era o sangue de Cristo, para expulsar-lhes os supostos feitiços que eram a causa de seu adoecimento, promovendo ainda, tal qual o Trem, esfregações para a retirada dos supostos feitiços e administrando remédios internos à

42Ibidem. 
base de ervas. É igualmente recorrente na fala das testemunhas que a arrumação da "mesa" era composta por bebidas infusas em ervas (principalmente vinho, mas aparece também menção a uma garrafa de cachaça), velas acesas, "quadros de santos" e "folhas e ervas" que, ao que parece, não eram usadas diretamente nas infusões e remédios, mas deveriam possuir funções de culto, uma vez que se encontravam, igualmente, dispostas no altar.

Não se pode esquecer que Olegário, filho de uma escrava, nascera (por volta do ano de 1863) numa região que vivenciara uma forte expansão agrícola e a montagem de grandes propriedades produtivas, destacadamente de café e, sendo assim, de forte concentração de população escrava. A escravidão na província do Espírito Santo era bastante peculiar,com altíssimos índices de reprodução endógena de seus plantéis e um forte processo de crioulização, mesmo em momentos anteriores à lei de $1850 .{ }^{43}$ Contudo, há que se notar também uma presença relevante de africanos Centro-Ocidentais, que chegavam a partir do porto do Rio de Janeiro, configurando entre $1790 \mathrm{e}$ 1821 mais de $90 \%$ dos africanos cativos do local. Realidade que, a despeito da diminuição dos níveis de africanidade, continuaria pelas décadas subsequentes, contribuindo, assim, para a ocorrência de trocas e novos aprendizados e "reafricanizações" de crenças e ações. Tal experiênciapermitiu constantemente, para nos valermos das palavras e leituras de Slenes, que a "África fosse redescoberta no Brasil" "4

Nesse sentido, encontramos em sua "dança macabra", conforme aparece (des)qualificada nos papéis da Justiça, fragmentos de cosmologias e crenças religiosas da África Centro-Ocidental, mas que foram, dinâmica e criativamente modificadas, com base especialmente nas práticas devocionais católicas vividas pela população do Império. Aqui concordamos, no fundamental, com Gabriela Sampaio: "assim,

43 MERLO, Patrícia Maria da Silva. Opcit.CAMPOS, Adriana P. Escravidão e Creolização: a capitania do Espírito Santo (1790-1815). In: FRAGOSO, João et al. Nas Rotas do Império. Vitória: EDUFES, 2014,pp.529-562. p. 535.

44 SLENES, Robert Slenes. “Malungo, ngoma vem!”: África coberta e descoberta do Brasil. Revista USP,São Paulo, pp. 48-67,1992. p. 49. 
buscar origens em outros contextos não quer dizer procurar algum tipo de "pureza", como se houvesse uma forma cultural permanente e imutável [...] o que se pretende é procurar referências a partir das quais as práticas culturais se transformam"45.

Nesta perspectiva, havia uma crença compartilhada entre diversos grupos da Âfrica Centro-Ocidental da existência de um complexo religioso comum calcado na ventura/desventura. Em síntese, acreditavam em um universo bom e harmônico, provedor de saúde, prosperidade, fecundidade, garantidas graças a um sem-número de rituais, oferendas, diversificados cultos a espíritos tutelares (os bisimbi, na cosmologia Kongo), entre outras formas de contatos com o "outro mundo". Entretanto, tal "ventura" poderia ser constantemente afetada pela ação de indivíduos mal intencionados e a manipulação de forças malévolas que desferiam desequilíbrio e agruras, ou se preferirmos, "desventura".

Essa mediação era realizada por indivíduos que detinham o contato com o "outro mundo", geralmente sacerdotes, e que eram presenças bastante carismáticas e com grande poder de persuasão dentro de suas comunidades. Olegário possuía esse traço. Várias de suas testemunhas sublinharam o crédito que as pessoas davam às suas "mesas", aparecendo no processo termos como "famoso Olegário", "bom curandeiro". Não faltaram, inclusive, pessoas que o defendessem em momentos em que fora criticado ou alertado de que suas práticas incorriam em erros e crimes. Outro traço bastante presente nesse complexo religioso é o peso dos rituais coletivos, marcados, em âmbito geral, pela existência de cânticos e danças que induziam ao transe e ao contato com o "outro mundo"

45 SAMPAIO, Gabriela. Pai Quibombo, o chefe das macumbas do Rio de Janeiro imperial. Revista Tempo,Niterói,Universidade Federal Fluminense,n.11, pp. 157-169, jul. 2001.p. 166.

46 SLENES. Op. cit., p. 58. SLENES, Robert. A árvore de Nsandatransplantada: cultos kongode aflição e identidade escrava no Sudeste brasileiro (século XIX). In: LIBBY, Douglas;FURTADO, Junia. Trabalho livre trabalho escravo. Brasil e Europa, séculos XVIII e XIX.São Paulo: Annablume, 2006. p. 287 e seguintes. THOMPSON, Robert Farris. Flash of the spirit. New York: Vintage Books, 1984. p.88-92. 
Acreditamos que essa chave de leitura é reforçada no caso aqui analisado a partir da fala de que Olegário, em suas cerimônias, no momento do transe parecia entrar em contato com o "outro mundo" a partir da invocação de Tata Jamby, Santa Maria e Marietta e que seus auxiliares (cúmplices, na linguagem policial) eram chamados de cambones ${ }^{47}$, termos de "língua banto". É possível que "Jamby" que as testemunhas ouviram fosse uma referência a Zambi (ou Nzambi) que, de acordo com Ramos, era como se nomeava em Angola a divindade suprema e criadora, adorada por parte expressiva dos "bantos" e que poderia possuir representações antropomórficas ${ }^{48}$. A fala das testemunhas, no entanto, não nos dão muitos elementos para explicações mais conclusivas.

As invocações realizadas por Olegário, quando se encontrava em transe, de nomes como "Marietta", "Tata-Mano Ouro" e "Tata-Cambone" nos remeteao culto de espíritos tutelares e ancestrais que mediavam as ações terrenas e deveriam, por isso, ser alvos de uma série de devoções e cerimônias para garantir a saúde e a prosperidade comunitária, bastante presentes na África Centro-Ocidental, como também em outras partes do Continente ${ }^{49}$. De acordo com Slenes, o termo "tata” possui variantes muito próximas para diferentes línguas da região Congo-Angola e grande alcance semântico, tendo a conotação de "pai", mas que igualmente referia-se à ideia de "liderança" Assim, ao que parece, nosso curador de Viana lançava mãoda evocação desses espíritos tutelares para livrar dos supostos feitiços aqueles que o procuravam.

47 A expressão (ou cambono) é até hoje usada em rituais de Umbanda para definir os "ajudantes" dos terreiros, aqueles que prestam serviço às entidades quando incorporadas, entre outras funções rituais.

48 RIBAS, Oscar. Usos e costumes angolanos. Salvador: Universidade da Bahia, 1964. p. 49-50; RAMOS, Artur. As culturas negras. Rio de Janeiro: Casa do Estudante do Brasil, 1943. p. 164-165 e 184.

49 SLENES, Robert. A árvore...Op. cit.,p. 286. RAMOS, Artur. Op. cit.,p.168.THORTHON, John. AÁfrica e os africanos na formação do mundo Atlântico (1400-1800). Rio de Janeiro: Campus, 2004. p. 196-198. 50 SLENES. Malungu... Op. cit.,p.61. 
Outro aspecto a ser sublinhado e que recorrentemente aparece na fala das testemunhas para as ações do curador de Viana é a manipulação de "folhas" e "ervas".Tanto na produção de suas beberagens como no momento em que punha "as mesas", essas "ervas" apareciam dispostas e arrumadas em seu altar, ao que parece, como mais um elemento de culto. Assim, a estreita relação entre domínio da natureza e práticas religiosas, entre outras atribuições voltadas para a cura das doenças do corpo e do espírito dos africanos centro-ocidentais, também é posta em tela nas pesquisas de Thompson. O autor afirma que dentro da cosmovisão Kongo, a garantia da harmonia e da "ventura" vinculava-se ao domínio das "raízes" e "ervas” pelos sacerdotes, que protegiam e curavam indivíduos e sociedades ${ }^{51}$. Contudo, não devemos perder de vista que para os habitantes de outros quadrantes africanos, como na África Ocidental, a exemplo dos "minas” e "jejes", igualmente muitotraficados para o Brasil no curso do século XIX, o contato e manipulação das "folhas" "ervas" não seria menos sagrado ${ }^{52}$.

Constatamos, ainda, nas práticas de descoberta de feitiços e cura aqui estudadas uma série de elementos que mostram o peso do catolicismo e de suas multifacetadas vivências, muitas delas, aliás, marcadas por reinterpretações e diferenças de olhares e fazeres em relação ao que preconizava a ortodoxia romana ${ }^{53}$.

Assim, Olegário dizia que os "anjos se apoderavam de seu corpo", dando-lhe poder para "fazer tudo o que queria", mesclando, desse modo, as danças, cânticos e o transe e a crença no catolicismo. Não nos parece absurdo supor que, nesse processo de crioulização com elementos católicos, o culto aos espíritos tutelares possa ter sido as-

51 THOMPSON, Robert Farris. Op. cit.,p. 107-108.

52 VERGER, Pierre. Notas sobre os cultos aos Orixás e Voduns na Bahia de Todos Santos, no Brasil, e na Antiga Costa dos Escravos, na África. São Paulo: Edusp, 2000. p. 87 e p. 227-230. PRANDI, Reinaldo. Segredos guardados. Os orixás na alma brasileira. São Paulo: Cia das Letras, 2005. p. 125-155; PARÉS, Luis Nicolau. A Formação do Candomblé: História e ritual da nação jeje na Bahia. Campinas: Editora da Unicamp, 2006. Cap. 4 e 7.

53 REIS. Op. cit.,cap. 4;ABREU, Martha. O Império do Divino - Festas religiosas e cultura popular no Rio de Janeiro (1830-1900). Rio de Janeiro, Nova Fronteira, 2000. p. 35 e seguintes. 
sociado à lembrança da intercessão dos anjos. Além disso, algumas testemunhas, a exemplo de Argemiro Pereira Ramos, que alegara ser amigo de Olegário, relataram que em seus cânticos eram lembrados o Padre Nosso e a invocação do nome de Santa Maria (que aparecem igualmente na fala das testemunhas na forma de orações), bem como a existência de "quadros de santos" - infelizmente, sem a menção específica aos mesmos - entre os apetrechos que usava ao "botar mesa”. Outra percepção sui generis do catolicismo, esta lembrada de modo quase unânime pelas testemunhas, seria tomar seus compostos de vinho (e, por vezes, cachaça) e ervas das quais se valia para expulsar os feitiços de seus clientes como o "sangue de Cristo".

Em resumo, a despeito de encontrarmos elementos rituais nas práticas terapêuticas do curador de Viana que nos remetem às crenças e ações engendradas na África Centro-Ocidental, não devemos pensar, em consonância com as análises de autores como Gabriela Sampaio, que tais eram transplantadas (a expressão é usada por Sweet) das diversas partes da(s) África(s) de forma "pura", como se por mero atavismo tais crenças e fazeres pudessem se apresentar intactas de um lugar ou período para o outro e se manter imaculadas em meio a processos históricos tão impactantes como a experiência do cativeiro. No caso aqui estudado, é evidente uma pulsante crioulização com diversos elementos do culto católico que, como era igualmente comum no Brasil, passava por vivências por vezes originais e comungadas por diferentes estratos sociais. Além disso, havia um complexo conjunto de traduções, escolhas, mudanças, por vezes de difícil compreensão para o pesquisador atual, que marcavam a maior ou menor - ou mesmo o apagamento da - presença de certas características de tais crenças e práticas.

\section{Clientes, ganhos, validações e desafetos}

Conforme apontado em vários outros estudos acerca da atuação daqueles que curavam sem a devida chancela da medicina oficial no Espírito Santo da segunda metade do século XIX, Trem e Olegário se valeram igualmente de seus conhecimentos terapêuticos para anga- 
riarem para si respeito, visibilidade, dinheiro e bensque garantiam seu sustento.

Na fala das testemunhas, no caso do Trem, são revelados alguns dos valores recebidos pelo curador. Para tratar de "uma rapariga" que era escrava de um Sr. Cabral, teria cobrado nove mil réis, valor devidamente pago pelo dono da escrava. Ao escravo Benedito cobrara mais dois mil réis para livrar-lhe de "uma ferida incurável na perna"54. De modo análogo, Olegário também ganhou dinheiro e bens para "botar mesa" aos enfermos. Assim, ao retirar feitiços de Quintino Lira dos Santos, recebeu como pagamento "uma joia de ouro", cobrando em outra ocasião sessenta mil réis pela cura de Bernardo João dos Passos, que se recusoua pagar, ficando acordado o valor de cinco mil réis "para os anjos".

Além disso, chama atenção no caso de Olegário a extraordinária mobilidade espacial que possuía ao ofertar suas "mesas" para curar de feitiços. Residindo em Viana, curava na capital - distante atualmenteaproximados trinta quilômetros-, em Santa Isabel,a aproximados vinte e três quilômetros, dentre outros rincões. Realidade que igualmente acusa a existência de redes de sociabilidade e companheirismo que, decerto, envolviam a estada, a alimentação e o abrigo desses curadores. Em alguns casos, Olegário pousava na própria residência daqueles que estava a curar.

Como é possível notar a partir do exposto acima, a clientela dos curadores era bastante diversificada. Procuravam seus préstimos escravos, mulheres e homens mestiços e pobres, mas, igualmente, indivíduos mais abastados e que, ao que parece pela fala das testemunhas, possuíam lugar de relevo nos espaços sociais em que habitavam e que recorriam às curas de feitiço para remediarem seus parentes e escravos.

Por outro lado, curar de feitiço, em geral, também significava apontar supostos feiticeiros, o que acabava por gerar tensões sociais entre as pessoas da comunidade. No processo contra o Trem, essa

54 Processo 527. Caixa 688. 1879. Arquivo Público do Estado do Espírito Santo. 
realidade se faz notar quando do depoimento da crioula Angélica, que desmente a história do curador de que teria botado feitiços para prejudicar Urbana.De modo análogo, Olegáriodevia angariar ódios e inimizades ao apontar supostos feiticeiros. Assim agiu dizendo que Lourenço Pinto da Vitória teria feito feitiços contra a sua mulher. Chamado em juízo como testemunha, Lourenço, além de desmentir o curador, ainda o acusou de ter matado sua mulher em função de suas terapêuticas - crime que igualmente pesava contra Olegário em seu processo - e por ter entrado em sua casa também com o intuito de "seduzir a filha dele, como de fato seduziu, tirando-a da casa do marido e carregando-a para o mato". O marido da moça, também chamado em juízo como testemunha contra o curador, confirma a história. Realidade que, uma vez mais, nos fala do carisma e do provável fascínio que envolvia a sua figura.

Resumindo, para os casos aqui analisados do Espírito Santo, é possível corroborar uma realidade que já vem sendo há tempos tratada pela historiografia que se debruça sobre as práticas de curar: a questão da escolha dos curandeiros, não raro, passava ao largo de uma eventual "falta de médicos" 55 . Relacionava-se, antes, à crença na eficácia que muitos desses indivíduos angariavam ao tratar das doenças e doentes, sendo vistos por suas comunidades como pessoas próximas, que possuíam um convívio assíduo com as pessoas do lugar (ainda que, como visto, tais convívios também fossem permeados por tensões). Essa percepção muitas vezes não era aplicada aos médicos, por serem considerados indivíduos "de fora" - não era incomum os médicos diplomados oferecerem seus serviços de modo mais ou menos itinerante-,que tinham diferentes explicações para as doenças e suas possibilidades de tratamento e que ainda por cima

55 Entre outros estudos, conferir:NOGUEIRA, André Luís Lima. Op. cit.CHALHOUB, Sidney. Cidade Febril: cortiços e epidemias na Corte Imperial.São Paulo: Companhia das Letras, 1996. WITTER, Nikelen Acosta. Males e Epidemias: sofredores, governantes e curadores no sul do Brasil (Rio Grande do Sul, século XIX). 2007. Tese (Doutorado em História Social). Universidade Federal Fluminense, 2007. WEBER, Beatriz Teixeira. As Artes de Curar - Medicina, Religião, Magia e Positivismo na República Rio-Grandense - 1889-1928. Santa Maria: Ed. da UFSM; Bauru: EDUSC - Editora da Universidade do Sagrado Coração, 1999. 
"cobravam caro" pelas suas curas. Assim, para muitas dessas pessoas, independentemente de sua condição financeira e/ou lugar social, a opção pelo curador não licenciado seria uma opção voluntária e, como se acreditava, mais eficaz que a do "médico formado". Portanto, concordamos aqui com a perspectiva de Witter de que para além das chancelas e diplomas, havia o que a autora nomeou "bom conceito" como um elemento bastante significativo da escolha desses terapeutas - fossem representantes da medicina douta ou curadores ilegais - por aqueles que estavam doentes ${ }^{56}$.

Além disso, conforme os argumentos desenvolvidos por Chalhoub ${ }^{57}$ acerca das "leituras africanas" em torno da varíola, não era incomum a realidade de que determinadas concepções de adoecimento e suas possibilidades de cura estavam mais próximas das crenças e explicações dos curadores ilegais, em geral compartilhadas pelos mais variados habitantes das comunidades nas quais atuavam, que da "medicina dos miasmas" que vigorava na Faculdade de Medicina, nos periódicos médicos e em outros espaços e discursos vindos dos saberes médicos oficiais. Realidade que também nos ajuda a entender tais preferências, a despeito de um processo intenso de institucionalização da medicina douta e da perseguição de indivíduos como o Trem e Olegário.

Infelizmente não há em nenhum dos dois processos as sentenças proferidas contra os réus. Devemos lembrar que no processo de Olegário, além das sanções previstas nos artigos 157 e 158 do Código Penal, ainda pesava contra ele o assassinato da mulher de Lourenço, em razão de suas curas. No texto do Artigo 158 constava que se a prescrição ilegal de medicamentos resultasse em mortes, a pena de prisão poderia variar entre seis e vinte e quatro anos. Por outro lado, na fala de várias das testemunhas havia a construção de versões que validavam suas práticas como curandeiro e a importância que tais indiví-

56 WITTER, Nikelen Acosta. Dizem que foi Feitiço: As práticas de Cura no Sul do Brasil. 1840-1880.

Porto Alegre: EDIPUCRS, 2000. p. 99 e seguintes.

57 CHALHOUB, Sidney. Op. cit.,p. 120-128. 
duos possuíam para as comunidades em queatuavamcom bastante desenvoltura e circulação espacial. Ainda que, a partir da proclamação da República, o país tenha assistido auma verdadeira cruzada das autoridades republicanas, em que a medicina oficial foi empreendida contra os "espíritas" e "charlatães", não seria possível, com base no material empírico disponível, afirmar enfaticamente que as sentenças mais pesadas que os referidos artigos do Código Penalimputavam aos seus transgressores tenham sido proferidas contra essaspráticas.

Seja como for, acreditamos que os dois processos aqui analisados, em vista do ineditismo das fontes e da praticamente inexistente literatura acerca da temática das práticas terapêuticas ilegais na Província e no Estado do Espírito Santo, podem estimular o debate e a produção de novos trabalhos nessa seara.

\section{Fontes e bibliografia}

\section{Fontes}

Processo 527. Caixa 688. 1879. Arquivo Público do Estado do Espírito Santo. Processo 1.466. Caixa 745. 1899.Arquivo Público do Estado do Espírito Santo. CHERNOVIZ, Napoleão.Dicionário de medicina popular... Paris: A. Roger e F. Chernoviz, 1890.

COLEÇÃO de leis do Brasil. Decreto $n^{\circ} 847$, de 11 de outubro de 1890 . Disponível em: <http://www2.camara.leg.br/legin/fed/decret/1824-1899/ decreto-847-11-outubro-1890-503086-publicacaooriginal-1-pe.html>. Acesso em: 18 mar. 2018.

RELATÓRIO com que o Barão do Itapemirim primeiro vice-presidente da Província do Espírito Santo apresentou na abertura da Assembleia Legislativa Provincial no dia 23 de maio de 1857. Victoria: Typographia Capitaniense de P. A. d'Azeredo, 1857. 


\section{Bibliografia}

ABREU, Martha. O Império do Divino - Festas religiosas e cultura popular no Rio de Janeiro (1830-1900). Rio de Janeiro, Nova Fronteira, 2000.

ALGRANTI,Leila Mezan. O feitor ausente: estudos sobre a escravidão urbana no Rio de Janeiro (1808-1822). Rio de janeiro: Vozes, 1988;

BELTRÃO, Jane Felipe. A arte de curar dos profissionais de saúde popular em tempo de cólera: Grão-Pará do século XIX. História, Ciências, Saúde-Manguinhos, Rio de Janeiro, n. 6, pp. 833-866, set. 2000.

BOURDIEU, Pierre. The specificity of the scientific field and the social conditions of the progress of reason. Social Science Information, v. 14, n. 6, pp. 19-47, 1975.

CÂMARA, Raphael Americano. Cotidiano, violência e criminalidade na comarca de Vitória/ES, a partir dos autos criminais (1841-1871). 2013. 170 f. Dissertação (Mestrado em História). Centro de Ciências Humanas e Naturais, Universidade Federal do Espírito Santo, Vitória, Espírito Santo, 2013.

CAMPOS, Adriana P. Escravidão e Creolização: a capitania do Espírito Santo (1790-1815). In: FRAGOSO, João et al. Nas Rotas do Império. Vitória: EDUFES, 2014, pp. 529-562.

. Nas barras dos tribunais: Direito e escravidão no Espírito Santo do século XIX. Tese (Doutorado em História). Instituto de História, Universidade Federal do Rio de Janeiro, Rio de Janeiro, 2003.

CARVALHO, Keila. A saúde pelo progresso: a regulamentação do trabalho médico no governo Vargas (Minas Gerais, 1930-1940). Rio de Janeiro: Multifoco, 2015.

CHALHOUB, Sidney. Cidade Febril: cortiços e epidemias na Corte Imperial. São Paulo: Companhia das Letras, 1996.

- Trabalho, lar e botequim: o cotidiano dos trabalhadores do Rio de Janeiro da Belle Époque. 2. ed. Campinas/São Paulo: Editora da Unicamp, 1986.

CHEVALIER, Jean;GHEERBRANT, Alain. Dicionário de símbolos. Rio de Janeiro: José Olympio, 1998.

EDLER, Flávio C. Medicina no Brasil imperial: clima, parasitas e patologia tropical. Rio de Janeiro: FIOCRUZ, 2011.

;GUIMARÃES, Maria Regina C. Chernoviz e a medicina no Império. Insight Inteligência (Rio de Janeiro), Rio de Janeiro, n.23, pp. 128-146, 
2003.

FERREIRA, Luís O. Medicina impopular: ciência médica e medicina popular nas páginas dos periódicos científicos (1830-1840). In: CHALHOUB, Sidney et al. (org.). Artes e ofícios de curar no Brasil: capítulos de história social. Campinas: Editora Unicamp, 2003.

FERREIRA, Roquinaldo. "Ilhas crioulas": o significado plural da mestiçagem cultural na África atlântica. Revista de História, São Paulo, n. 155, $2^{\circ}$, pp. 17-41, 2006.

FIGUEIREDO, Betânia Gonçalves. A arte de curar. Cirurgiões, médicos, boticários e curandeiros no século XIX em Minas Gerais. Rio de Janeiro: Vício de Leitura, 2002.

FRANCO, Sebastião Pimentel. A instrução feminina na visão dos presidentes da província do Espírito Santo (1845-1888). In: ; SÁ, Nicanor Palhares (org.). Gênero, etnia e movimentos sociais na história da educação. Vitória: Edufes, 2011.

- Do privado ao público: o papel da escolarização na ampliação de espaços para a mulher na Primeira República. 2001. 295 f. Tese (Doutorado em História Social). Faculdade de Filosofia, Letras e Ciências Humanas, Universidade de São Paulo, São Paulo, 2001.

- O terribilíssimo mal do Oriente: o cólera na província do Espírito Santo (1855-1856). Vitória: Edufes, 2015.

HOCHMAN, Gilberto; ARMUS, Diego (org.). Cuidar, controlar, curar em perspectiva histórica: uma introdução: ensaios históricos sobre saúde e doença na América Latina e Caribe. Rio de Janeiro: Editora Fiocruz, 2004.

KODAMA, Kaoriet al. Mortalidade escrava durante a epidemia de cólera no Rio de Janeiro (1855-1856): uma análise preliminar. História, Ciências, Saúde-Manguinhos, Rio de Janeiro, v. 19, pp. 59-79, 2012. Suplemento 1.

MACHADO, Roberto et al. Danação da norma. Medicina social e construção da Psiquiatria no Brasil.Rio de Janeiro: Graal, 1978.

MATTOS, Hebe Maria de Castro. Das cores do silêncio: os significados da liberdade no sudeste escravista-Brasil, século XIX. 2. ed. Rio de Janeiro: Nova Fronteira, 1998.

MERGÁR, Arion. A representação do gênero feminino nos autos criminais na Província do Espírito Santo (1853-1870). 2006. 160 f. Dissertação (Mestrado em História). Centro de Ciências Humanas e Naturais, Universidade Federal do Espírito Santo, Vitória, Espírito Santo, 2006. 
MERLO, Patrícia Maria da Silva. O nó e o ninho: estudo sobre a família escrava em Vitória, Espírito Santo, 1900-1871. 2008. Tese (Doutorado em História). Instituto de História, Universidade Federal do Rio de Janeiro, Rio de Janeiro, 2008.

NOGUEIRA, André Luís Lima. Entre cirurgiões, tambores e ervas:calunduzeiros e curadores ilegais em ação nas Minas Gerais (século XVIII). Rio de Janeiro: Garamond Universitária, 2016.

ORO, Ari Pedro. Considerações sobre a liberdade religiosa no Brasil. Ciências $\&$ Letras, n. 37, pp.433-447, 2006.

PARÉS, Luís N. O Processo de crioulização no Recôncavo baiano. Afro-Ásia, Salvador, n. 33, pp. 87-132, 2005.

. A Formação do Candomblé: História e ritual da nação jeje na Bahia. Campinas: Editora da Unicamp, 2006.

PEDRO, Joana Maria. Processo judiciais como fonte histórica: a concretude e o uso. In: SIMPÓSIO NACIONAL DE HISTÓRIA, 26., 2011, São Paulo. Anais do XXVI Simpósio Nacional da Associação Nacional de História São Paulo: ANPUH, 2011.

PRANDI, Reinaldo. Segredos guardados. Os orixás na alma brasileira. São Paulo: Cia das Letras, 2005.

RAMOS, Artur. As culturas negras. Rio de Janeiro: Casa do Estudante do Brasil, 1943.

REIS, João J. A morte é uma festa. Ritos fúnebres e revolta popular no Brasil do século XIX.São Paulo: Cia das Letras, 1999.

RIBAS, Oscar. Usos e costumes angolanos.Salvador: Universidade da Bahia, 1964.

SÁ JR. Mário. Fé cega justiça amolada. O controle do Judiciário sobre as práticas religiosas afro-brasileiras no nascimento da República (1891-1946). Revista Brasileira de História das Religiões,Maringá, v. III, n. 9, pp. 1-9, jan. 2011. Disponível em: <http://www.dhi.uem.br/gtreligiao/pub. html . Acesso em: 20 mar. 2018.

. Malungos do sertão. Cotidiano, práticas mágicas e feitiçaria no Mato-Grosso setecentista.Tese (Doutorado em História). Faculdade de Ciências e Letras de Assis, Universidade Estadual Paulista, 2008.

SAMARA, Eni Mesquita. A família brasileira. 2. ed. São Paulo: Brasiliense, 1986. 
SAMPAIO, Gabriela. "Curandeiros e Charlatães": reflexões sobre medicina, crença e cura na primeira década republicana. mneme - revista de humanidades, Caicó, v. 15, n. 34, pp. 37-53, jan./jun. 2014.

. Nas Trincheiras da Cura. As diferentes medicinas no Rio de Janeiro Imperial. São Paulo: Editora daUnicamp, 2001.

. Pai Quibombo, o chefe das macumbas do Rio de Janeiro imperial. Revista Tempo, Niterói, Universidade Federal Fluminense, n. 11, pp. 157169, jul. 2001.

SATO, Maria Cristina Martinez. Pobreza e conflito (1860-1935). São Paulo: Annablume, 2001.

SCHWARCZ, Lilia. Espetáculo das raças:cientistas, instituições e questão racial no Brasil (1870-1930). São Paulo: Cia das Letras, 1993.

SILVA, Maria Beatriz Nizza da. Sistema de casamento no Brasil colonial. São Paulo: Edusp, 1984.

SLENES, Robert Slenes. "Malungo, ngoma vem!": África coberta e descoberta do Brasil. Revista USP,São Paulo, pp. 48-67, 1992.

A árvore de Nsandatransplantada: cultos kongode aflição e identidade escrava no Sudeste brasileiro (século XIX). In: LIBBY, Douglas; FURTADO, Junia. Trabalho livre trabalho escravo. Brasil e Europa, séculos XVIII e XIX. São Paulo: Annablume, 2006.

SOARES, Geraldo. Esperanças e desventuras de escravos e libertos em Vitória e seus arredores ao final do século XIX. Revista Brasileira de História, v. 26, pp. 79-114, 2006.

SOIHET, Rachel. Vivências e formas de violência: mulheres pobres e ordem urbana (1890-1920). Rio de Janeiro: Forense Universitária, 1989.

SOUZA, Alinaldo Faria de. Entre a reclusão e o enfrentamento: a realidade da condição feminina no Espírito Santo a partir de autos criminais (18451870) - desmistificando estereótipos. 2007. 143 f. Dissertação (Mestrado em História). Centro de Ciências Humanas e Naturais, Universidade Federal do Espírito Santo, Vitória, Espírito Santo, 2007.

SOUZA, Laura de Mello e. O diabo e a Terra de Santa Cruz: feitiçaria e religiosidade popular no Brasil colonial. São Paulo: Cia das Letras, 1995.

SWEET, James H. Recriar África.Cultura, parentesco e religião no mundo afro-português (1441-1770). Lisboa: Ed. 70, 2007.

THOMPSON, Robert Farris. Flash of the spirit. New York: Vintage Books, 
1984.

THORTHON, John. A África e os africanos na formação do mundo Atlântico (14001800). Rio de Janeiro: Campus, 2004.

VERGER, Pierre. Notas sobre os cultos aos Orixás e Voduns na Bahia de Todos Santos, no Brasil, e na Antiga Costa dos Escravos, na África. São Paulo: Edusp, 2000.

WEBER, Beatriz Teixeira. As Artes de Curar - Medicina, Religião, Magia e Positivismo na República Rio-Grandense - 1889-1928. Santa Maria: Ed. da UFSM; Bauru: EDUSC - Editora da Universidade do Sagrado Coração, 1999.

WITTER, Nikelen; MOREIRA, Paulo Roberto S. "Praticando a magia e seus sortilégios": feitiçaria e curandeirismo nos primórdios da República. In: DILLMANN, Mauro (org.). Religiões e religiosidades no Rio Grande do Sul: matriz afro-brasileira. vol. 4. São Paulo: ANPUH, 2016, pp. 21-48.

WITTER, Nikelen Acosta. Dizem que foi Feitiço: As práticas de Cura no Sul do Brasil. 1840-1880. Porto Alegre: EDIPUCRS, 2000.

Males e Epidemias: sofredores, governantes e curadores no sul do Brasil (Rio Grande do Sul, século XIX). 2007. Tese (Doutorado em História Social). Universidade Federal Fluminense, 2007.

XAVIER, Regina. Dos males e suas curas. Práticas médicas na Campinas oitocentista. In: CHALHOUB, Sidneyet al. (org.).Artes e oficios de curar no Brasil: capítulos de história social. Campinas: Editora da Unicamp, 2003.

ZENHA, Celeste. As práticas da justiça no cotidiano da pobreza. Revista Brasileira de História, São Paulo, v. 5, n. 10, pp. 123-146, mar/ago. 1995.

Recebido em: 23/06/2018 - Aprovado em: 15/11/2018 